\title{
A Study on Functional Translation of Proper Nouns in Traditional Chinese Opera*
}

\author{
Guangtao Cao \\ School of Foreign Languages \\ Shaoguan University \\ Shaoguan, China
}

\author{
Linrong Qiu \\ School of Foreign Languages \\ Shaoguan University \\ Shaoguan, China
}

\author{
Jiexin $\mathrm{Wu}$ \\ School of Foreign Languages \\ Shaoguan University \\ Shaoguan, China
}

\begin{abstract}
Chinese Opera has a glorious history. Because of language barriers, discrepancy of drama culture and dramatic performance systems, it is still quite difficult to appreciate Chinese opera in actual cross-cultural overseas context. This paper collects and translates a part of proper nouns of Chinese operatic stage. From three translating methods of proper nouns in Chinese opera based on the SF theory - literal translation, liberal translation and transliteration with notes to transliteration, this paper concludes that we should choose an adaptive translating method of proper nouns in accordance with different functions.
\end{abstract}

Keywords - translation of Chinese opera; proper nouns in Chinese opera; cross-culture communication

\section{INTRODUCTION}

Opera constitutes an important part of Chinese literature and stage art. The translation of Chinese opera has been going on for many years. Yet there remains a serious problem in drama translation studies. Susan Bassnett ever reminds us: "It is quite clear that theatre is one of the most neglected areas. There is very little material on the special problems of translating dramatic texts, and the statements of individual theatre translators often imply that the methodology used in the translation process is the same as that used to approach prose texts."'[1] Opera as one of the branches of the theatre is in a same quandary. How to translate the typical Chinese Cultural Characteristic statement into a language as used by a native speaker has become the duty of opera translators. Traditional Chinese opera has its special beauty appreciation system and way of presentation. Therefore, during the translation the translator

*Fund Project: 1. Guangdong Provincial Social Science Planning Project "A Study on the English Translation of Chinese Operas from the perspective of Data Base" (GDI1XWW10);

2. Shaoguan City Social Science Planning 2016 "A Study on the English Translation of Lingnan Operas" (G2016004);

3. Guangdong University Student Innovation and Entrepreneurship Project "A Functional Research on the English Translation Assessment Modes of Chinese Opera Classics” (201810576014). should lay special emphasis on proper nouns, such as characters, clothing and props and so on. Chinese opera translation is an important approach of traditional Chinese culture, which is confronted with a lot of problems. Firstly, Chinese opera translation itself possesses difficulty; secondly, the proper noun in Chinese opera has no fixed methods on translation; what's important, we are lack of capable persons in this area. Through studying and classifying proper nouns of Chinese opera, this paper sums up the specific translation strategies and methods in Proper nouns of Chinese Opera.

The main function of translation of Chinese opera is to spread Chinese opera to Western audiences. The translation of some special words in Chinese opera should be focused on how much the foreign audiences would get it. Translators should concentrate on the rigorous effect as well as the comprehensiveness of proper nouns in Chinese Opera, involving the interaction with both verbal and nonverbal languages.

Translation of classical Chinese opera especially proper nouns in Chinese opera is a great and complicated system engineering to achieve sustainable development. This great project needs active involvement of drama scholar at home and abroad as well as the support and assistance of the relative authorities of China.

Unified translation of terms has been a formidable problem in scientific translation due to the complexity of various terms. As a result, it also has become a concerned focus in academy. This paper analyses the translation of proper nouns in three traditional ways: literal translation, liberal translation, transliteration/notes to transliteration.

\section{LITERAL TRANSLATION}

Literal translation is widely used for opera translation which keeps the general words, phrases and sentences of source language and keeps the meaning of the original. In the course of translation, a translator deals with sentences from both its basic forms and the whole text. The English 
language is not allied to the Chinese, but they have something in common. There exists generality. That is, the two languages that are otherwise dissimilar can find their generality with the help of literal translation. And it also puts the content of source language into words as accurately as possible. All these things that target-reader might comprehend immediately can be translated into English directly.

Generally, a lot of opera props can be translated literally. Take Chinese work Shuxin “书信” for example: as a kind of stage property, Shuxin “书信” expresses the same meaning both in Chinese and English, so it can be ,letter" literally.

Other examples for literal translation:

Chinese word Tilan “提篮” is translated into ,basket".

Chinese word Saozhou “扫帝” is translated into ,broom“e

Chinese word Jinyin “金银” is translated into ,gold and silvere.

Chinese word Yunpian “云片” is translated into ,cloud scenery ${ }^{\text {ee }}$ which means the view of cloud and mist.

Chinese word Shoukao “手铐” is translated into ,handcuffs ${ }^{e e}$.

Chinese word Chuanjiang “船桨” is translated into ,paddle

Chinese word Wawa “娃娃” is translated into ,dolle .

Chinese word Xingli “行李” is translated into ,luggagee.

Chinese word Zhutai “烛台” is translated into ,candle stickee.

Chinese word Denglong “灯笼” is translated into, ,lantern".

Chinese word Shoujuan “手绢” is translated into ,handkerchief .

Chinese word Qipan “棋盘” is translated into ,chessboard ${ }^{\text {ee }}$.

Chinese word Susan “素半”is translated into, plain umbrella ${ }^{e e}$.

Chinese word Guai “拐” is translated into ,crutch“. arrowe

Chinese word Gongjian “弓箭” is translated into ,bow and

Chinese word Diaoyugan “钧鱼笔” is translated into ,fishing $\operatorname{rod}^{\text {ee }}$.

Chinese word Fujie “符节” is translated into ,tally“.

Chinese word Bishou “七首” is translated into ,dagger"e.

\section{LIBERAL TRANSLATION}

Liberal translation is a translation method by which a translator should get to know the culture of both source language and target language and have extensive knowledge. [2] Proceeding from the meaning and spirit of the original, Liberal translation does not keep its sentence patterns, figures, metaphor or others. By literal translation, a translator needs to conform to the same standards in both Chinese and English; on the contrary, liberal translation is loose and gives translators a huge amount of creative latitude. The two translation methods are quite different in thoughts. Many vocabularies in Chinese opera involve the customs and traditions or strong ethnic characteristics of China. This kind of words is better translated into English by liberal translation. A translator needs to grasp their truly meaning in opera and then combine with the cultural nature and language information of target language. This requires that opera translators should know the Chinese and the western, the ancient and the contemporary, and deeply understand the connotation of Chinese opera. The advantage of liberal translation is that it turns out to be faithful to the original but not rigid, flexible but not excessive and gives translator a huge amount of creative latitude. From the point of liberal translation, target-reader can get to know the cultural icon and connotation made by Chinese opera.

The function of liberal translation is to reach Yan Fu's standard of translation, intelligible ${ }^{e e}$. The most basic concept of liberal translation is that of the ,intelligibilitye. The translation has to write down to all its target-reader and achieve the objective - cross-cultural communication. It needs to convey the meaning of the original text to the target language and be accepted.

In translation of proper nouns in Chinese opera, translators better understand the intention and contemporary significance of all kind of things in traditional Chinese opera. Such translation can vividly display its essence and gets easy for the target-readers to remember. For example, Qiang “枪” in Chinese opera is free translated as ,spear ${ }^{\text {re }}$. Anybody who knows general knowledge about Chinese opera can see that this Qiang “枪” is like a weapon with a long shaft, typically of steel and a pointed tip, don not simply mean a ,gun "e in English. So translators need to translate Qiang “枪” as ,spear rather than ,gun "e Yunluosan “云罗伞” and Hongluosan “红罗 半” cannot be literal translated as ,cloud umbrella"e and ,red umbrella" as well. Yunluosan “云罗伞” and Hongluosan “红罗 半” refer to a cover made of gorgeous golden cloth that is fixed above a bed, seat as a decoration or as a shelter, general used by royalty. Therefore, these two should be suitably translated as ,cloud umbrella ${ }^{e e}$ and, red umbrella ${ }^{\text {ee }}$ The following shows more examples:

\section{A. Chinese Word Yunzhou “云帚” Is Liberally Translated as ,Whisk"}

Yunzhou “云帚”, used by eunuchs and servant girls in some plays, is an important prop of opera stage. Generally it is white, but Mei Lanfang “梅兰芳” used a green one in opera Luoshen “洛神” and Cheng Yanqiu “程砚秋” used a purple one in opera Hongfuzhuan “红拂传”. Translators should translate into whisk as its meaning, not literal translate into ,cloud broom"e.

\section{B. Chinese Word Qiang “枪” Is Translated into ,Spear" \\ Chinese word Danqiang “单枪” is translated into ,single spear $^{\text {ee }}$}


Chinese word Shuangqiang “双枪” is translated into ,double headed spear"e.

Chinese word Ruanqiang “软枪” is translated into ,flexible spear"e

Qiang “枪” in opera don not simply mean a ,gun ee in English, it means ,spear"e. In particular, Ruanqiang “软枪” cannot easy to be translated into ,soft spear", because Ruan “软” in this phrase means that it can bend or be bent easily. Instead of ,softe, ,flexible ${ }^{\text {ee }}$ would be more appropriate. Shuangqiang “双枪” cannot be literal translated as ,double speare because it means a two-headed spear. The correct translation of Shuangqiang “双枪” is ,double headed Spear".

\section{Chinese Word Bucheng “布城” Is Translated into „City Wall as Setting"}

On the state, Bucheng “布城” is used to represent the city tower which has well and gate. Translators cannot simple translate into ,city wall ${ }^{\text {ee }}$ but ,city wall as settinge

\section{Chinese Word Zijingun “紫金棍” Is Translated into „Violet Gold Rod"}

It is a prop used by eunuchs. It looks like a stick with gold pattern on both ends.

\section{E. Chinese Word Kaichang “开场” Is Translated into "Scene Openers"}

„Opener" in English refers to the first event in a play, here refers to the first scene of opera.

\section{TRANSLITERATION AND NOTES TO TRANSLITERATION}

Transliteration can function as the complement of lexical gaps between Chinese and English languages. When lexical gap occurs, transliteration may act as a bridge in communication. [3] When vocabulary vacancy exists between SL and TL, translation cannot be an equivalent in Chinese, and translator can think about transliteration.

In general, note-to-transliteration mode provides an expression or a text with a gloss or glosses so that targetreaders could understand it better. Qimo “砌末” (opera props) is the unique prop of traditional Chinese ancient opera and is rather different from the western weapons. The weapons held by different character all have the particularity. Hence, literal translation is not suitable in such part. For protecting deep cultural connotations for the Chinese nation, it is better to translate with transliteration or notes to transliteration.

Examples for transliteration:

- Chinese word Shuo “槊” is translated as ,Shuo, Shuo's slimming head is cone shaped, double pointed knife, whose two ends lacquered with tin. Golden shuo is tied with a red tassel and its handle is in lacquered gold. ,

- Chinese word Zhua “挝” is translated as ,Zhua, A combination of gold coin shuo and splitting sky shuo. The character holds it in each hand in order to fight. The gold coin shuo is a six flap coin which can be turned. It has a 4 feet long handle. The splitting sky shuo is shaped like a clenched fist holding a pen. Its handle is 2 feet long. Both of them are in lacquered gold. ${ }^{\text {e }}$

- Chinese word Tang “镗” is translated as ,tang/ trident, Named as ,wildgoose tangecommonly, it is lacquered gold. The left and right sides of the tanges head have two branches bent to the knife."

- Chinese word Ji “戟” is translated as , ji/halberd, also known as painted $\mathrm{ji}$, which is divided into single winged and double winged. Single winged ji is lacquered tin, one side of its head has a crescent halberd edge with a tassel hanging on it. Double winged $\mathrm{ji}$ is also lacquered with tin, both sides a crescent halberd edge and a tassel hanging. ${ }^{\text {.e }}$

It is very important of the rehearsal terms in Chinese opera and the writer chooses several significant proper nouns of rehearsal, such as Qiba “起霸”, Zoubian “走边”, Tangma “趟马”, Bazi “把子”, Satou “酒头”, Qiaogong “跷功”. The rehearsal terms, like those, are the unique terms in Chinese culture of traditional opera which cannot be equivalent in English language. Nevertheless, notes to transliteration not only can display their cultural meanings but also acquaint Western readers with the tradition of China.

Examples for notes to transliteration:

- Chinese word Qiba “起霸” is translated as ,qiba, it is a kind of choreographed movements, displaying how the generals in ancient prepare for a battle and showing battle atmosphere as well as the disposition and emotions of the generals. It is also shows the generals using mime to put on and checking his battle armor.e $^{\text {ee }}$

- Chinese word Zoubian “走边” is translated as ,zoubian, it is a kind of choreographed movements, displaying the actors moving from one scene to another while showing her or his information for the plot."

- Chinese word Tangma “趟马” is translated as ,tangma, it is a kind of choreographed movements, displaying the actors who ride a horse on the stage while showing the character's emotions and disposition at the mean time.

- Chinese word Bazi “把子” (Bazigong) is translated as ,bazi-training/ weapon training, refers to a character for performing exercises with fake weapons and training her or his fighting skills."

- Chinese word Satou “酒头” is translated as ,satou, Performing exercises, also known as suppressed face, to show the character in the spirit of fear and anger."

- Chinese word Qiaogong “跷功” is translated as ,qiaotraining, performing exercises, which likes the toe shoes used in ballet, displaying the ladies in Chines opera'bound feet'and it is still the beauty standard for ladies in the 20 th century. ${ }^{\text {e }}$ 


\section{CONCLUSION}

According to Functional theories, translators may use proper translating methods to adapt different functions. Literal translation, liberal translation and transliteration/notes to transliteration are the main methods. Translators should adapt different translating methods according to different kinds of opera vocabulary, for different occasions and different context. This means that translation is the subject to so many factors like function, context and medium.

In translation of proper nouns in Chinese opera, however, many questions remain to be solved. Chinese opera translation involves many traditional Chinese opera knowledge. This is very challenging and greatly influences the translation. At present, the translation of proper nouns in Chinese opera still lacks of adequate research.

\section{REFERENCES}

[1] Bassnett, Susan. Still trapped in the Labyrinth[A].Constructing Cultures. Essays on Literary Translation[C].Clevedon: Multilingual Matters Ltd. , 1998:119.

[2] Song Hong, Literal Translation and Free Translation[J]. Happy Reading, 2013(22):54

[3] Shen Wei, The Application of Transliteration in Translating Chinese Traditional Xiqu[J]. Overseas English,2017(2): 129-131. 